REVISTA ANDALUZA DE ANTROPOLOGÍA.

NÚMERO 8: TURISMO DE BASE LOCAL EN LA GLOBALIZACIÓN

MARZO DE 2015

ISSN 2174-6796

[pp. 45-67]

http://dx.doi.org/10.12795/RAA.2015.i08.03

Fecha de Recepción: 29-12-2014

Fecha de Aceptación: 20-02-2015

\title{
TURISMO DE BASE LOCAL EN GALICIA: ECO- AGROTURISMO ARQUEIXAL O LA EXCEPCIÓN CULTURAL COMO MODELO
}

\author{
Xerardo Pereiro \\ Universidade de Trás-os-Montes e Alto Douro
}

\section{Resumen.}

En Galicia, y en un contexto de nuevas ruralidades, el turismo rural ha seguido siempre una política de substitución de la agricultura. De hecho, desde la aparición del desarrollo de turismo rural, fueron mínimos los casos de abertura de proyectos agroturísticos. Desde diferentes perspectivas esa política ha fracasado y no ha conseguido las buenas intenciones pretendidas de desarrollo rural y freno para el despoblamiento. En nuestro texto empezaremos por contextualizar esas políticas para luego ilustrar algunas de sus implicaciones territoriales y humanas. Galicia, a diferencia de otros territorios europeos, no ha apostado seriamente por modelos agroturísticos y menos por modelos turísticos de base local donde las comunidades fueran realmente protagonistas. Pero en los últimos años hay señales de cambio en algunos proyectos y microterritorios de la ruralía gallega. Es el caso de Arqueixal, un proyecto ecoagroturístico ubicado en el centro de Galicia que promueve un turismo rural responsable y de base local. Además de ello, Arqueixal lidera la organización del festival rural "Son d'aldea", donde la participación local es central en la organización de un turismo no folclorizante ni idealizante, sino consciente y consciencializador de las relaciones entre pasado y presente.

Palabras clave.

Ecoagroturismo, turismo de base local, turismo rural, Galicia, Arqueixal. 


\begin{abstract}
.
In Galicia, and in a context of new ruralities, rural tourism has always followed a policy of substitution of agriculture. In fact, since the appearance of the development of rural tourism, cases were minimal opening agritourism projects. From different perspectives, that policy has failed and has not gotten alleged good intentions of rural development and brake depopulation. In our paper we begin to contextualize these policies and then illustrate some of their territorial and human implications. Galicia, unlike other European territories, has not seriously opted for agritourism models and least locally based tourism models where communities were actually actors. But in recent years there are signs of change in some projects and small territories. Arqueixalis an eco-agri-tourism project located in the center of Galicia that promotes responsible tourism and rural community based-tourism. Moreover, Arqueixal leads the organization of rural festival "Son d'aldea" where local participation is central for the organization and the consciousness of visitors about the relations between past and present.
\end{abstract}

\title{
Keywords.
}

Ecological agritourism, local community based tourism, rural tourism, Galicia, Arqueixal.

\section{INTRODUCCIÓN}

Desde la conquista de la autonomía de Galicia a finales de los años 1970, las políticas de desarrollo rural en Galicia han utilizado el turismo rural como sustituto de las actividades agropecuarias. Las unidades de turismo rural creadas (hoy más de 500) se han centrado generalmente en las infraestructuras de alojamiento y son mínimos los casos de abertura de proyectos agroturísticos. Desde diferentes perspectivas críticas esa política ha fracasado y no ha conseguido las buenas intenciones pretendidas de desarrollo rural y freno para el despoblamiento, principalmente del interior (cf. Trabada Crende, 2007). En nuestro texto empezaremos por contextualizar esas políticas para luego ilustrar algunas de sus implicaciones territoriales y humanas.

Galicia a diferencia de otros territorios europeos no ha apostado seriamente por modelos agroturísticos y menos por modelos turísticos de base local donde las comunidades fueran empoderadas y realmente partícipes y protagonistas de su propio desarrollo. Pero en los últimos años hay señales de cambio en algunos proyectos y microterritorios de la ruralía gallega. Es el caso de Arqueixal, un proyecto ecoagroturístico ubicado en el centro de Galicia que promueve un turismo rural responsable y de base local. Además de ello, Arqueixal lidera la organización del festival rural "Son d'aldea", celebrado el primer 
fin de semana del mes de septiembre de cada año, donde la participación local es central en la organización de un turismo cultural no folclorizante ni idealizante, sino consciente y consciencializador de las relaciones entre pasado y presente.

En nuestro texto, y siguiendo una estrategia metodológica etnográfica de análisis de la excepción cultural, pretendemos elucidar sobre los problemas y las oportunidades de producir una forma diferente de hacer turismo de base local. Nuestro objetivo es reflexionar sobre la relación entre agricultura y turismo rural. Para ello tomaremos como referencia a Arqueixal ecoagroturismo, un caso de estudio que no es representativo de la realidad del turismo rural en Galicia, antes por el contrario es una excepción cultural en la diversidad. Pero su particularidad es bien significativa, pues nos muestra nuevos caminos de relación entre la agroganadería y el turismo rural.

La elección de este caso de estudio se justifica en: a) la importancia que este proyecto ha tenido y está teniendo en la exportación de una nueva forma de entender la ruralidad y el turismo rural en Galicia; b) nuestro conocimiento antropológico longitudinal y transversal con seguimiento del caso desde su nacimiento en el año 1989, debido a estar localizado en una zona donde hemos desarrollado trabajo de campo antropológico desde finales de los años 1980 y que concluyó en la producción de una tesis doctoral sobre las relaciones entre lo rural y lo urbano en Galicia (ver Pereiro, 2005); c) la excepcionalidad cultural como forma de aumentar el conocimiento sobre la diversidad turístico-cultural. La metodología utilizada para la construcción de este texto ha sido la etnografía antropológica, articulando la observación participante longitudinal con las entrevistas informales con la familia Carrera Valín, sus trabajadores y sus clientes, el análisis documental y la ciberetnografía. Además de ello, y bajo mi orientación científica, dos ex-alumnos de nuestra licenciatura en antropología aplicada, Gonçalo Mota e Ivett Krezet, han disfrutado de una beca Leonardo da Vinci (2009-2010) para investigación e intervención social en Arqueixal. Su trabajo ha consistido en investigar para construir una imagen pública del proyecto, culminada en la elaboración de la página web (http:// www.arqueixal.com) y dos documentales antropológicos. Todo ello me ha permitido construir un conocimiento cercano y familiar de una realidad próxima culturalmente pero compleja desde el punto de vista de la mirada antropológica.

Subrayar aquí que el concepto de turismo de base local es ambiguo y que está muy relacionado con el de turismo comunitario (Murphy, 1985; Gascón, 2013). Es difícil encontrar una definición adecuada para esos dos conceptos en la literatura científica (cf. Richards y Hall, 2000; Ruiz Ballesteros, 2011; Cañada, 2012; Gascón, 2013). Desde mi punto de vista, el turismo de base local es una metáfora que la literatura científica utiliza para lo que el mercado turístico clasifica como turismo comunitario, algo muy popularizado en las últimas décadas en algunos lugares del mundo, producto de los movimientos sociales a favor de turismos alternativos y responsables. 
El turismo de base local es una mirada del turismo desde las personas y su forma de organizarse en colectividad, que actúan de forma estratégica para controlar recursos de un territorio y obtener de él lo necesario para vivir. En este sentido, consideramos que no hay un modelo de turismo de base local aplicable universalmente, porque los contextos y las poblaciones locales son diversos. Por ello, los principios y la filosofía del turismo de base local (ej. la auto-organización y la distribución de los beneficios) se adaptan creativamente a los diferentes contextos y poblaciones locales.

La comunidad y la base local no son un absoluto, y más bien son vagos e imprecisos términos para definir y delimitar a un grupo humano. El primero afirma su sentido de cohesión social y el segundo el sentido de anclaje territorial, y ligados al concepto de turismo han idealizado el grupo con fines comerciales. Además han homogeneizado y moralizado el grupo en cuestión y el turismo como buenos, frente a los turismos malos y las influencias externas consideradas muchas veces como negativas. Esta dicotomización ha llevado a una simplificación extrema de la diversidad y desigualdad interna en muchos grupos, pero también a la ocultación de las conexiones local-global, los flujos culturales, las relaciones sociopolíticas y económicas globales que afectan a los espacios glolocales. La base local o comunidad no son un grupo con atributos esenciales, ellos son una forma de manejar el desafío de vivir juntos y de gestionar recursos colectivos e individuales.

No queremos con ello minusvalorar las experiencias de turismo comunitario o de base local, más bien reflexionar sobre las diferentes formas de hacer turismo de base local y la diversidad de estrategias de acción. Del mismo modo, pensamos que no solamente la comunidad organiza turismo comunitario, sino que también el turismo, como campo de relaciones local-globales, puede contribuir a la organización de la comunidad. No podemos descuidar esta idea si queremos comprender mejor el turismo de base local, o mejor el turismo con base local, como tendremos ocasión de ver en el análisis etnográfico del caso de estudio que presento más adelante.

El turismo de base local no es tan local como lo pintan. Por un lado los agentes locales dependen de agentes globales (ej. mediadores o turistas), y por otro este tipo o modalidad de turismo se aprovecha de algo global que es el cambio del centro de atención del producto para el servicio y hoy en día la experiencia. Ese nuevo centro en la experiencia turística ha favorecido los proyectos turísticos de reencuentro con la naturaleza y la cultura de los nativos.

El texto que a continuación presentamos empieza por situar el caso de estudio en el contexto de las transformaciones de los espacios rurales en Galicia y el papel del turismo rural en esas mudanzas, para luego presentar el caso de estudio como ejemplo de turismo de base local. Concluiremos el texto con una reflexión final sobre el cambio de paradigma en el turismo rural de Galicia de un turismo sin agricultura a una agricultura con turismo responsable. 


\section{NUEVAS RURALIDADES Y TURISMO RURAL EN GALICIA}

Los espacios rurales se están redefiniendo globalmente y de manera particular en Europa (Cloke, Marsen y Mooney, 2006; Van der Ploeg, 2010, Silva y Figueiredo, 2013) y en la Península Ibérica (García Sanz, 1994; Pereiro, 2005; Roseman, 2008; Silva, 2009, Pereiro y Prado, 2013). Los denominados neorurales y rurbanos han adquirido cierto protagonismo en la reconstrucción, mirada y resignificación de los "viejos" espacios rurales, y han entrado en un proceso de diálogo con instituciones y otros protagonistas. Lo cierto es que estamos asistiendo a una serie de transformaciones sociales, económicas, políticas y culturales de los sentidos del lugar "rural” que es necesario repensar desde el punto de vista teórico, metodológico y también desde la intervención-aplicación. Desde esta óptica, entendemos el concepto de nuevas ruralidades (Oliva, 2010; Pereiro, 2011) como una herramienta analítica útil para comprender las transformaciones rurales contemporáneas.

Con datos del 2013 (IGE, 2013, ver www.ige.eu), Galicia contaba con una población de 2.765.940 habitantes, de los cuales 1.138.161 residirían en la provincia de Coruña, 955.050 en la de Pontevedra, 346.005 en la de Lugo y 326.724 en la de Ourense. Las cifras muestran una desigual ocupación del territorio, con una población concentrada en el litoral y en los centros urbanos, el despoblamiento rural no ha tocado fondo aún, pero este se produce más por envejecimiento y fallecimiento de la población más vieja, que por movilidad demográfica hacia los núcleos urbanos. Este despoblamiento, sobre todo de las provincias de Lugo y Ourense, hay que verlo en perspectiva histórica como parte de un proceso de urbanización compleja. Según el Instituto Gallego de Estadística (fuente: $\underline{\text { www.ige.eu }}$ ), en el año 2010 Galicia tenía 30.100 entidades singulares de población, 10.278 en núcleos y 20.491 en diseminado. De ellos, 26.997 tenían menos de 100 habitantes. En ese mismo año había 1.407 aldeas abandonadas (584 de la provincia de Lugo, 533 de la de Coruña, 140 de Pontevedra y 130 de Ourense), 827 con un único habitante censado.

Pero estos datos estadísticos pueden desviar la atención de otros indicadores y procesos de transformación que apuntan a un tiempo de nuevas ruralidades y un repoblamiento incipiente. Si bien el número de explotaciones agrarias ha disminuido considerablemente, hasta el punto de que algunos hablan del final del campesinado gallego (Cabana Iglesia, 2008; González Reboredo, 2009), también es cierto que entre 1999 y 2009 la superficie media por explotación agrícola ha aumentado en un 45,9\% (fuente: Censos agrarios de España), el mayor aumento del estado español, aunque a pesar de ello las explotaciones rurales gallegas siguen siendo relativamente pequeñas. Estas representaciones estadísticas no dejan de tener una cierta miopía, pues pese a ello la pequeña agricultura familiar continua a reproducirse sin aparecer en la estadística y sin ser digna de medición socioeconómica oficial (Carreira y Carral, 2014). 
Esta miopía estadística lleva a infravalorar algo que en Galicia es fundamental: la agricultura es un modo de vida y no solamente una actividad económica empresarial y capitalista. La pequeña agricultura sentimental o agricultura de precisión (Carreira y Carral, 2014) continúa a ligar rural y urbano, se reinventa en los centros de las ciudades gallegas y sigue siendo un valor importante para gran parte de la población, bien como productores o como consumidores, genera rentabilidad económica y está ayudando a salir de la "crisis" a muchas familias gallegas. Por lo tanto hay resistencia y autonomía de la pequeña agricultura familiar gallega, aunque muy distribuida por el territorio y sin una medición estadística oficial.

Los espacios rurales gallegos son hoy parte de una región urbana desde el punto de vista social, cultural, político y económico. No vale ya la dicotomía rural/urbana para explicar o entender la realidad gallega, por mucho que legislaciones, políticas e imaginarios continúen a utilizarla en Galicia, hay ya un urbanismo sin ciudad o también desde otra mirada un rurbanismo antropológico (Pereiro, 2005). Lo rural ha perdido autosuficiencia y ha aumentado su dependencia urbana, pero también es cierto que ha cambiado su significado simbólico en el mercado global.

Galicia ha pasado en las últimas décadas, de ser una sociedad rural agraria a una sociedad urbana pos-agraria y posmoderna, que ha cambiado su mirada con relación a su ruralidad, patrimonializando y naturalizando esta. En este proceso el campesino gallego no desaparece, sino que ha cambiado con el tiempo, como siempre ha sucedido. Y si bien son un grupo social cuantitativamente menor que antaño, este se ha renovado y adaptado a los nuevos tiempos produciendo de forma no exclusivamente capitalista y subordinada frente a los grandes capitales (Palerm, 1997). Los espacios rurales gallegos han disminuido su función de producción alimentar y han cambiado sus funciones y significados por los de consumo de ocio y servicios de recreación, tranquilidad, turismo rural, bienestar, etc.

Esta diversificación multifuncional de los espacios rurales gallegos lleva a: a) un nuevo poblamiento rural, cuantitativamente aún no importante, pero sí cualitativamente relevante; b) la atribución de nuevos usos y sentidos sociales a las ruralidades; c) la diversificación de los agentes sociales en interacción; d) el pendularismo rural-urbano y el aumento de la población vinculada a lo rural (ej. fines de semana); e) la conversión del agro (espacio de producción agrícola) en paisaje para contemplación y disfrute. Y si bien no existe un único rural gallego, sí que estos procesos de contraurbanización se están produciendo bajo diferentes formas en todo el territorio galaico.

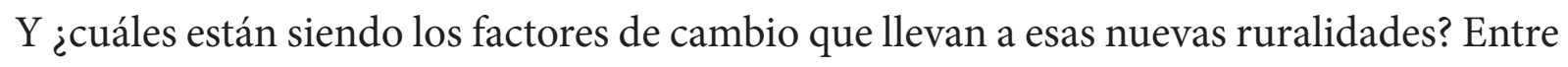
los procesos socioeconómicos estructurales destacan el impulso del tardo capitalismo, la globalización, el consumismo, la contaminación insostenible, las agresiones al medio ambiente, los abusos de poder de la agroindustria capitalista, y la "crisis"... Entre los 
procesos ideológicos destacan el pastoralismo (Marx, 1964; 1976), el naturalismo, la patrimonialización (Smith, 2006), el ambientalismo (reservas, parques...), el ecologismo y otros movimientos sociales de reivindicación (ej. el decrecimiento, el turismo sostenible o el turismo responsable). Estos procesos ideológicos no están exentos de una cierta idealización y de un cierto romanticismo que mitifica un pasado rural exento de dureza e de culturas de trabajo difíciles. Entre los procesos sociales destacamos las nuevas culturas de movilidad urbano-rural, las nuevas valorizaciones de los productos agroecológicos y "saludables", las huidas del estrés urbano, el repoblamiento rural gallego por extranjeros, y la venta de casas rurales.

Estos factores de cambio que crean nuevas ruralidades están produciendo también nuevos paisajes culturales en los cuales el turismo rural tiene un papel importante. El turismo rural se presentó en Galicia como una panacea del desarrollo rural; era un turismo rural colindante pero ajeno al mismo tiempo a la agricultura y pensado solamente para mantener alguna población en el medio rural. Pero el modelo seguido ha sido el desarrollo del turismo en espacio rural, y no un verdadero modelo de turismo rural o agroturismo, el turismo ha actuado así como un sustituto de la agricultura y no como un complemento o dinamizador de la actividad agraria.

Este proceso condujo a la práctica inexistencia de agroturismo (Rodil Fernández, 2009) y las sucesivas legislaciones no han sabido o querido corregir esta tendencia (ej. Decretoley del 2 de junio de 1995 de ordenación de los establecimientos de turismo rural; Ley 9/1997 de 21 de agosto de ordenamiento del turismo en Galicia; Decreto 191/2004, del 29 de julio, de estabelecimientos de turismo rural de Galicia -DOGA, 10-8-2004-; Ley 7/2011, del 27 de octubre del turismo de Galicia). Entendemos el agroturismo como un tipo de turismo desarrollado en explotaciones agrícolas, significando un rendimiento complementar de la actividad agrícola (Phillip et al., 2010; FleischeryTchetchik, 2005). En esas explotaciones es fundamental el consumo turístico de productos alimentares producidos allí mismo, por lo tanto hay una relación intrínseca entre agricultura y turismo, mediada por la comida y los productos de calidad.

Sin embargo, y a pesar de ello, el turismo rural de Galicia representa un signo de esas nuevas ruralidades de las que hablamos, su oferta ha aumentado con el paso del tiempo, ya en el 2003 presentaba 436 establecimientos y en 2010 llegaba a su tope en 538, disminuyendo desde entonces hasta los 520 unidades en el 2013. La capacidad de alojamiento también aumentó hasta 2010 (6.632 plazas) y desde entonces no para de disminuir, así en 2013 tenía 6.493 plazas (fuente: IGE, www.ige.eu). Esta oferta turística presenta una paradoja de distribución territorial, pues los establecimientos son más abundantes en las provincias litorales de Coruña y Pontevedra, que en las provincias de interior de Lugo y Ourense, consideradas más "rurales". Podemos observar esta distribución geográfica en la siguiente tabla: 
Tabla 1: Alojamientos de turismo rural de Galicia en 2013

\begin{tabular}{|l|l|l|}
\hline 2013 & $\begin{array}{l}\text { Número de } \\
\text { establecimientos }\end{array}$ & Número de plazas \\
\hline Galicia & 520 & 6.493 \\
\hline A Coruña & 152 & 1.880 \\
\hline Lugo & 131 & 1.654 \\
\hline Ourense & 74 & 960 \\
\hline Pontevedra & 163 & 1.998 \\
\hline
\end{tabular}

Fuente: IGE, 2013

En el año 2003 ya tenemos datos importantes de demanda con 114.270 turistas rurales, en un 90\% españoles (49\% gallegos, 20\% de Madrid) y solamente 10\% extranjeros (Sparrer, 2007: 58). En el año 2011, el número de turistas rurales sube a 142.793 y los extranjeros ya representan un 14,1\%. En el año 2013 esa cifra baja a 129.179 turistas lo que muestra el parón en la demanda de este tipo de turismo (fuente: INE, www.ine.es). A diferencia de Portugal (Silva, 2009), nuestro país vecino, donde la demanda de turismo rural es en un $70 \%$ de extranjeros, el caso español y gallego presentan fundamentalmente una demanda estatal interna, donde los turistas parecen tener una cierta nostalgia y atracción rural luego de un intenso proceso de urbanización desde la década de 1960.

Son muchas las críticas realizadas a las políticas de desarrollo del turismo rural gallego (Pardellas, 1996; Valcárcel Ribeiro y Santos Solla, 1999; Prado Conde y Pereiro, 2012; Pereiro, 2012), pero una constante en esas críticas apunta al marco legal restrictivo de la primera legislación, la baja ocupación (10,8\% en 2013, fuente: IGE, www.ige.eu), la poca rentabilidad económica y la falta de producción de productos turísticos rurales integrados que combatan realmente la estacionalidad, fijen población y dinamicen las economías rurales. Según datos del Instituto Nacional de Estadística el turismo rural en Galicia solamente da trabajo a 818 personas (ver www.ine.es). Esos puntos críticos de la investigación turística señalan la necesidad de una segunda generación de turismo rural (Lane, 2014) en Galicia, con trabajo en red, innovación, planificación desde abajo y más relación experiencial con la agricultura y los residentes en el rural. 
Todos estos datos contextuales son importantes porque nuestro caso de estudio va a demostrar que otra política de turismo rural es posible. En Galicia, las ayudas públicas al turismo rural gallego no favorecieron en casi ningún caso a los agricultores. Es más, los establecimientos que en teoría son agroturísticos (las "casas de labranza") no lo son en la realidad, por lo que a diferencia de otras comunidades autonómicas españolas que han apostado claramente en el agroturismo, en Galicia, considerada históricamente como una comunidad rural y agrícola, el agroturismo no tiene una implementación importante. En el caso gallego, el turismo rural de Galicia no ha conseguido aumentar la producción agraria, no se ha articulado con el tejido económico local y ni siquiera ha sido capaz de convertirse en una actividad rentable económicamente, pero mucho menos de fijar mucha población y crear gran empleo en el rural.

Por ello podemos concluir aquí que hubo una desproporción entre las inversiones y los impactos esperados (Santos, 1999; Martínez Roget, 2004; Lois et al, 2009; Santos e Paul, 2011), que el turismo rural ha representado un discurso ideológico, retocando con estética folclorista, barnizando el dramático cambio rural y creando escaparates de tradiciones inventadas para consumo urbano, vendiendo los restos del naufragio de comunidades rurales (Prista, 1998). El turismo rural gallego ha sido más bien útil para promover una cierta especulación inmobiliaria protagonizada en muchos casos por una cierta burguesía urbana de las pequeñas ciudades gallegas. Por lo tanto el turismo rural en Galicia no ha revitalizado el medio rural pero sí que ha contribuido a transformarlo al mismo tiempo que ha sido producto y resultado de esa transformación.

\section{AGROTURISMO ARQUEIXAL COMO EXCEPCIÓN CULTURAL EN LA DIVERSIDAD}

Arqueixal es una granja familiar situada en la aldea de Albá (de unos 70 habitantes), municipio de Palas de Rei (comarca de la Ulloa, provincia de Lugo, comunidad autonómica de Galicia), que cuenta con 30 hectáreas de superficie en su explotación agraria. Arqueixal nace como proyecto en el año 1989 por iniciativa de Xosé Luis Carrera Valín, siguiendo la tradición familiar de sus padres quienes habían creado a lo largo de sus vidas una pequeña explotación agraria (policultivo minifundista). Luis es el segundo de 4 hermanos, ha estudiado magisterio (educación) y es una persona sensibilizada con la ecología y el medio ambiente (cf. Pereiro, 2012; González Sousa, 2013).

A su regreso de la ciudad decide innovar en la explotación y negocia con sus padres y familia esa innovación sobre la tradición. El introduce vacas de raza parda (más queseras) en vez de las frisonas (más lecheras) y de las rubias gallegas (más orientadas a la producción cárnica), que han perdido producción lechera, aumenta el tamaño de la explotación, cuida los pastos y la alimentación de las vacas con mimo y esmero. Podríamos 
decir que Luis es un "avanzado" para su tiempo, finales de los años 1980, cuando el queso de la actual Denominación de Origen Arzúa-Ulloa no tenía ni el prestigio ni el peso económico global que tiene en la actualidad, siendo el tercero de España en volumen de producción (Frutos Mejías y Ruíz Budría, 2012).

El proyecto fue un poco "contracorriente", en palabras de su promotor, pues apostó en la producción de queso en un momento en que aumentaba en España el consumo de leche pero no de queso. Con el paso de los años, el queso de vaca que producía Arqueixal fue obteniendo reconocimiento nacional e internacional, ganando premios y prestigio (ej. primer premio del Ministerio de Agricultura 2001 al mejor queso de pasta blanda de leche de vaca). A este reconocimiento contribuyó decisivamente el Aula de Productos Lácteos de la Universidad de Santiago (campus de Lugo), quien con su papel investigador $\mathrm{y}$ asesor ha hecho mejorar las cualidades organolépticas del queso de esta granja y también de otras de la zona.

Posteriormente, a inicios del siglo XXI, Luis desarrolla una nueva fase de innovación, y comienza a producir y comercializar queso, yogur y leche fresca de producción ecológica reconocida y certificada por la CRAEGA (Consejo Regulador de Agricultura Ecológica de Galicia). Esta nueva innovación le llevará a obtener nuevos reconocimientos (ej. primer premio del Ministerio de Agricultura 2007 al mejor queso ecológico de vaca). A esta producción ecológica destinará anualmente unos 160.000 litros de leche de producción propia, para la elaboración de quesos, yogures y leche ecológicos por este orden de importancia. A ello hay que añadir otros 120.000 litros de leche de pastoreo -obtenidos algunos en explotaciones de la zona- para su producción semi-artesanal de quesos (no ecológicos).

Hay que destacar que aproximadamente el $80 \%$ de la producción láctea de la explotación se destina a producción quesera, un $10 \%$ a yogurt y otro $10 \%$ a leche ecológica. En media cada queso necesita unos 6,5 litros de leche, y en general se utilizan aproximadamente unos 1000 litros de leche cada día de producción. Pero a pesar de ello y según su promotor "levamos un tempo que estamos decrecendo, pero non baixamos o rendemento" (entrevista, 31-03-2012), es decir trabajando menos producen no solamente con más calidad sino con más rentabilidad económica.

Desde el inicio del proyecto y una vez que se consolidó el relevo generacional y el liderazgo de la generación más joven representada por Luis, se fue acumulando un capital simbólico que atrajo a muchos visitantes. Con el paso del tiempo las visitas a la granja aumentaron, creándose así un canal 0 de comercialización, es decir, los productos llegaban directamente al consumidor sin mediación de mercados locales, regionales o globales. Este canal cero contribuyó y contribuye a la fidelización de sus clientes y a la identificación afectiva con sus productos. Las visitas permanentes de consumidores, 
científicos, curiosos y otros sirvieron de mecanismo reflexivo para concebir nuevos proyectos de educación ambiental y ecoturismo.

Es de esta manera como Arqueixal sigue innovando, adaptándose a los nuevos nichos de mercado, aprovechando su capital sociocultural y sus redes sociales, volviéndose poco a poco más holístico y diversificado, presentando a principios de la década del 2000 un proyecto ecoagroturístico con tres vertientes: 1) visitas (tienda, obradoiro, "parladoiro" -conversatorio-, aldea turística, 2) alojamiento turístico con actividades ecoagroturísticas y3) organización de recreaciones festivas por toda la aldea con participación comunitaria. El proyecto ecoagroturístico seguirá el asesoramiento de la Fundación Ecoagroturismo, asediada en Asturias, y contemplará la rehabilitación de una parte de la aldea de Albá (lugar de Eirexe) para alojamiento turístico. El proyecto va a recibir una ayuda del proyecto de desarrollo rural Agader, que alcanzó el 35\% de la inversión del proyecto.

Como resultado de esa nueva innovación han sido rehabilitados cuatro edificaciones rurales que se pueden definir como casas autónomas con derecho a cocina ("Palleira, Pallar das Ameixeiras, Casa do Muiñeiro, Caseta das Andoriñas"). La rehabilitación ha seguido el respeto por las tipologías arquitectónicas de esta zona del centro de Galicia y los principios de la bioconstrucción. Ha utilizado madera sostenible y aceites vegetales de poro abierto, protección contra el gas radón y sus efectos, corcho como aislante térmico, cal hidráulica con arena en las juntas de las piedras, para "que a casa respire" nos dice Luis (conferencia en Chaves, 11-05-2011), pinturas minerales ecológicas, barro cocido sin esmaltar. Además ha utilizado las energías renovables para suministro de calor y electricidad a las casas, solar térmica para agua caliente y fotovoltaica, lo que dota a los alojamientos turísticos de una cierta autosuficiencia energética.

En las camas de los alojamientos ha utilizado como ropa de abrigo lino, lana o algodón, pero no poliéster ni materiales sintéticos, para evitar así campos electromagnéticos. Además y siguiendo la filosofía feng-sui oriental ha orientado las camas Norte-Noroeste, para un mejor descanso de sus huéspedes. En las habitaciones tampoco encontraremos cajas de conexión eléctrica, evitando campos electromagnéticos y persiguiendo un mejor descanso de los visitantes. Estamos ante una materialización idealizada de la renovación de viejas ruralidades actualizadas, donde lo importante es la relación porosa e íntima entre tradición e innovación. Y si bien la rehabilitación de las casas de piedra ha sido realizada con fines turísticos, una de ellas, la casa de Rebordela, de unos dos siglos de antigüedad, ha quedado como testimonio de una casa-vivienda de inicios del siglo XIX. La "Rebordela" es una casa de muy pequeño propietario rural gallego que se ha convertido en una especie de casa-museo, museo de sitio o economuseo según la terminología del canadiense CirilSimmard (Simard, 1992). Es esta la materialización cultural de un nuevo concepto con nuevos contenidos (Roigé i Ventura, 2007) que articulan una empresa con un museo para que el patrimonio cultural se gane la vida. Esta vinculación entre producción 
económica y cultura busca el autofinanciamiento pero también la rentabilidad social y económica. En este economuseo se ofrece la posibilidad de alojamiento informal para los huéspedes que quieran evocar la vida pasada, pero lo más importante de la misma es que sirve de exposición contextualizada de la vida rural en una casa gallega de muy pequeños propietarios, lo que permite comparar el pasado y el presente de esta aldea. De esta manera este economuseo actúa para los visitantes como una especie de túnel del tiempo y para los locales una "casa antiga" que emblematiza algunas identidades locales. En palabras de su promotor, la Rebordela es"unha viaxe de descuberta dunha forma de vida autosuficiente dos tempos preindustriais" ( $\mathrm{cf}$ http://www.arqueixal.com/agro/ economuseo.htm).

Además de la rehabilitación integral de parte de la aldea, se ha construido ex-novo, aunque con una arquitectura integrada, un "parladoiro", es decir, un pequeño edificio multifuncional que sirve de espacio para conferencias, reuniones y encuentros con capacidad para 60 personas aproximadamente, recepción de grupos y visionado de documentales. El proyecto Arqueixal ecoagroturismo ha recibido la certificación CERES de la red internacional de ecoagroturismo y está integrado en la red española ECOTUR. Ello le ha posicionado en nichos de mercado segmentado más preocupado por el medio ambiente, la ecología y la cultura, según las nuevas tendencias del mercado turístico.

Además de la mano de obra familiar (4 personas), Arqueixal emplea a 6 trabajadores naturales de la zona, algunos de los cuales trabajan polifuncionalmente en la quesería y en el proyecto turístico. Este número de trabajadores es bastante elevado si lo relacionamos con el tamaño y la facturación no muy alta del proyecto, pero ello es debido a que una parte de su producción es artesanal y no le permite automatizar sistemas de trabajo en todos los procesos de producción (ej. fabricación manual del queso). Además hay que tener en cuenta que el $40 \%$ de los beneficios de Arqueixal son para los trabajadores, lo que representa una mayor repercusión en la mano de obra local y también una buena distribución de beneficios que cuida, mima y valoriza a los trabajadores y sus culturas del trabajo.

Arqueixal ecoagroturismo abrió oficialmente en mayo del año 2010 y la comunicación con los clientes se realiza a través del boca-oreja (ej. entre sus clientes), pero también por medio de una web (www.arqueixal.es)y su correo electrónico. Subrayar aquí que el cambio en la comercialización y en la comunicación con los clientes ha dado un salto cualitativo muy importante en la Galicia rural, pues del teléfono en la taberna o en casa se ha pasado a la posibilidad de utilizar Internet (ej. Satelital) en el medio rural gallego. Además de ello hay que considerar el gran impacto que Arqueixal ha tenido y tiene en los medios de comunicación audiovisual y escrita, lo que le ha permitido colocarse muy bien en los mapas experienciales de los consumidores. 
Desde su abertura oficial las visitas de día han aumentado exponencialmente hasta los alrededor de 2000 visitantes por año. Sin embargo, los turistas que se alojan en Arqueixal son muchos menos, alrededor de 200 anuales, que pagan entre 70 y 150 Euros por el alojamiento. Hoy en día las visitas (visitantes de día, consumidores en general y turistas) representan el $20 \%$ de los beneficios económicos del proyecto, y el $25 \%$ del total de la venta directa de productos lácteos en origen. A pesar de una pequeña bajada en el número de turistas en los dos últimos años, el cliente de Arqueixal es simiente que se esparce divulgando el proyecto, la zona y los valores e imágenes que se le asocian. Por lo que su mejor medio de comunicación con los mercados es el boca-oreja de los propios visitantes.

La demanda turística ha sido y es la de personas que quieren empaparse en la cultura del lugar y su medio ambiente, pero también conocer el lugar donde se producen los productos de Arqueixal que consumen habitualmente en sus hogares urbanos. Es un ejercicio socio-afectivo por medio del cual disminuye el valor monetario de la venta del producto (el precio), sin tener en cuenta el costo del transporte, y aumenta su valor simbólico, al reconocer el consumidor "o valor do produto no lugar de orixe" (Luis Carrera Valín, entrevista, 31-03-2012), es decir al reconocer su producción artesanal, manual, y su calidad, se produce un cambio en la percepción del valor simbólico de este producto y sus asociaciones simbólicas (rural, campo, agro, tradición).

Los turistas de Arqueixal proceden de Galicia (turismo de proximidad), Cataluña, País Vasco, Madrid y Levante español. Ellos vienen en parejas, familias con niños (con estancias más largas), grupos (estancias más cortas) y grupos de amigos. Ellos buscan un modelo de turismo sostenible, sobre todo los que vienen por medio de la red ECOTUR. Entre los excursionistas (visitantes de un día), estos vienen por medio de escuelas, universidades, escuelas agrarias, y "veñen ver o proxecto global, o concepto" (Luis Carrera Valín, 3103-2012).

El grado de implicación de los visitantes varía entre el ver, el observar y el hacer, pues las posibilidades de participación e integración son variadas. Entre las actividades que se realizan destacan la visita a la tienda, a la granja y a la aldea turística, el visionado de documentales, el acompañar las tareas agrícolas y ganaderas (ej. llevar las vacas a pastar, trabajar en la huerta ecológica, participar en la matanza del cerdo, la recogida de setas, castañas, elaboración de queso, pan, etc.), hacer rutas de senderismo o en bicicleta, visitas a puntos de interés del entorno (ej. castillo de Pambre, iglesia románica de Vilar de Donas, torrentes de Mácara en el río Ulla...).

En la experiencia turística (visita con alojamiento) o excursionista (visita sin alojamiento) de Arqueixal, el visitante se aproxima al conocimiento de la agricultura biológica (UE) u ecológica (España) (Reglamento de la CEE n. ${ }^{\circ}$ 2092/91 del Consejo del 24 de junio 
de 1991; reglamento de la UE n. ${ }^{\circ} 834 / 2007$ del Consejo de 28 de junio de 2007), que implica producir restringiendo la utilización de insumos externos, la no utilización de transgénicos, el respeto por el bienestar animal, el uso responsable del agua, de la energía, de los suelos y de otros recursos naturales. En su anclaje territorial gallego, la agricultura ecológica tiene un Consejo Regulador (Decreto 4/2007, de 18 de enero de 2007) que en estos momentos certifica ya más de 500 productos como ecológicos, entre los que están los de Arqueixal.

En palabras de su promotor, lo que más sorprende a los visitantes de Arqueixal es que inicialmente piensan que es un lugar abandonado y recuperado, pero al llegar allí ven que está todo integrado y que hay un encuentro con los locales. Y en la diversidad de estas experiencias turísticas hay que subrayar algunas por su significación de las nuevas ruralidades y el turismo responsable:

a) Una de ellas es el turismo de raíces de emigrantes gallegos en el País Vasco y sus descendientes, que retornan a sus orígenes buscando estas ruralidades y excluyendo el alojarse en las villas o capitales municipales. Son antiguos habitantes de la aldea hoy ya sin vivienda allí y con una relación previa con el lugar que se mantiene en sus memorias y que quieren mostrar a los hijos.

b) El turismo de tipo ecológico que proviene de Cataluña y protagonizado por clases medias acomodadas que tienen un interés especial por el consumo de un turismo más responsable.

c) La experiencia de una casa de turismo rural más, protagonizada sobre todo por gallegos residentes en los centros urbanos, que no valoran tanto la diferenciación y distinción ecológica del proyecto.

En general los visitantes suelen comentar que "la realidad supera a la de la página web", lo que representa que la expectativa imaginada o soñada ha sido superada por la experiencia y la práctica turística de esta modalidad turística.

\section{SON D'ALDEA: OTRA FORMA DE TURISTEAR LO RURAL EN GALICIA}

Arqueixal es un proyecto que con responsabilidad social corporativa (Figueira y Dias, 2011) pero también comunitaria contribuye para la dinamización de la comunidad envolvente, en este caso, la aldea de Albá, el municipio de Palas de Rei y la comarca de la Ulloa. A la preocupación por generar beneficios económicos se une la de generar tejido y redes sociales que se encuentran en las actividades del ciclo agrario anual y sus 
actividades de educación patrimonial, afirmando con ello una nueva visión de lo rural menos estereotipada, menos estigmatizada y no sin una cierta idealización bucólica.

Sin embargo una actividad destaca por excelencia, se trata del festival rural "Son d'aldea", un encuentro y una escenificación teatral de la vida de la aldea de Albá en los años 1940-50 que se celebró por primera vez el 3 de septiembre del 2011 (ver http:// www.youtube.com/watch?v=NPcZ2i91E8cy http://www.sondaldea.com/), que lleva ya cuatro ediciones y que fue organizado en colaboración con la asociación de vecinos "O Parzemique" y el grupo de teatro local "Metátese" dirigido por Afonso García Penas. "Son d'aldea" tiene dos partes celebradas en dos días consecutivos: a) un encuentro científico en Arqueixal alrededor de problemáticas del desarrollo rural y organizado por dos antropólogos nativos (Xerardo Pereiro y Santiago Prado); b) una "living history" o representación escenificada del pasado rural protagonizada por los propios vecinos de la aldea y de la comarca, coordinados por el escenógrafo y director teatral Afonso García Penas en sus tres primeras ediciones y en la cuarta por Aida Sánchez Expósito. Las actividades se preparan desde un año antes e integran una red de agentes sociales locales que fabrican un cemento social para unir en intimidad cultural las diversidades sociales y culturales locales.

Los promotores de la iniciativa se han inspirado en otras escenificaciones de lo rural como la "Romería Etnográfica Raigame" de Vila Nova de los Infantes (Celanova - Ourense). Esta romería, inspiradora de "Son d'Aldea", es promovida por el Grupo de Danzas de la Diputación Provincial de Ourense y el Centro de Cultura Popular Xaquín Lourenzo (ver http://www.romariaraigame.es/), cuenta ya con doce ediciones y se celebra coincidiendo con el día anual de las letras gallegas, el 17 de mayo. Esta ha tenido su inspiración en la visita que algunos de sus miembros realizaron a algunos parques temáticos históricos de los Estados Unidos, según nos relató uno de sus organizadores en la edición de 2011. Esto nos parece relevante para analizar los flujos culturales entre tradiciones y los procesos de espectacularización de la cultura. A su vez "Son d'aldea" se inspira también en los parques históricos y museos al aire libre escandinavos y algunos de sus promotores han visitado Suecia y algunos proyectos como el Skansen museo de Estocolmo.

Una breve descripción etnográfica de la performance de "Son d'Aldea" nos situó en el año 2011 como observadores participantes en uno de los seis grupos, de 35 personas aproximadamente, conducidos por un guía local vestido de época que nos acompaña en un recorrido por puntos de interés desde las 11:00 hasta las 14:00 horas. Subrayar que hay plazas limitadas para participar en este festival y que es necesario abonar previamente una tasa o pago que contribuye al autofinanciamiento de esta actividad y al control o límite de una participación no muy masificada de los visitantes. La actividad, en la cual el liderazgo de Arqueixal es fundamental, se autofinancia en un $80 \%$ y es apoyada por el Ayuntamiento de Palas de Rei, Caixa Rural Galega y la Diputación Provincial de Lugo. 
Empezamos nuestro recorrido acompañado de un grupo de gallegos, catalanes (de Pineda del Mar) y una antropóloga japonesa que está haciendo trabajo de campo en la zona. El primer punto de parada es el "Largo do Cruceiro", una de las plazas de la aldea donde el grupo folclórico de la ciudad de Lugo "María Castaña” y el grupo local de baile tradicional gallego "Buxaina" interpretaban una "foliada" (encuentro para bailar, cantar y divertirse celebrado tradicionalmente al caer la tarde).

El segundo punto de parada es la Casa de la Rebordela, una casa de piedra recuperada para escenario de la ruralidad de finales del siglo XIX. A esta pequeña vivienda de piedra de granito, los visitantes entran por la puerta del establo, donde una vaca rubia gallega y su ternerito comen y son exhibidos para los visitantes. En el "sobrado" o piso superior el visitante puede ver el dormitorio, las queseras y el mobiliario de la época junto con un antiguo telar. La salida del recorrido es por la "lareira" (cocina) donde tres mujeres de la zona actúan como productoras tradicionales de queso y establecen un diálogo irónico en gallego sobre cual la mejor forma de producir queso. Son representantes de tres generaciones de mujeres de la comarca que sintetizan formas de relación entre lo rural y lo urbano en Galicia. Una de ellas es nativa de la zona, está jubilada y ha sido una gran productora de quesos; otra es de una generación intermedia, vive en la villa o pueblo de Antas de Ulla y es periodista; la tercera es de una generación más joven y reside en la ciudad de Vigo, donde estudia teatro.

El recorrido continúa por los caminos de la aldea y un tercer punto donde se detiene el grupo es el de los canteros haciendo un muro de piedra y explicando el oficio de cantero a los visitantes. Aquí podemos ver ya una primera división de género en función de tareas adscritas localmente como más adecuadas. El cuarto punto de la visita organizada es la escuela, recreada en el patio de una casa rural, donde una antigua maestra de la aldea, sus jóvenes alumnos y un inspector reproducen la escuela de los tiempos de la dictadura franquista en un ambiente simbolizado materialmente por el crucifijo, la bandera española de la época, el retrato del dictador Francisco Franco y otros elementos. Uno de los temas centrales del guion escenificado es el conflicto lingüístico entre el gallego y el español, la subordinación, adaptación y resistencia de los hablantes en gallego. El cuadro presentado es también un cuestionamiento moralizante de los que piensan que hablar español es lo correcto en Galicia y hablar gallego es cosa de paletos y atrasados.

Posteriormente el grupo avanza hacia una casa donde se cuece el pan en un horno de piedra y más tarde el grupo se dirige a un prado donde los segadores "crabuñan" o preparan su guadaña para cortar la hierba. Seguidamente nos detenemos en otra casa donde dos hombres trabajan los cestos y la madera, y establecen un diálogo desgarrado sobre la mejor forma de trabajar las maderas. Sus conocimientos son profundos, son poliactivos pero dominan saberes y conocimientos sobre el bosque, los árboles y arbustos, el medio ambiente, la influencia de la luna y el tiempo atmosférico en la calidad de las maderas. 
Sus eco-técnicas son presentadas de una forma pedagógica para un público general no instruido en saberes técnicos y culturales de este tipo, sus interpretaciones utilizan el humor y la representación escénica para hacer pasar un rato agradable y aprender cosas al grupo.

La visita guiada por los escenarios campestres sigue y luego de una pequeña parada en un puesto de venta, gestionado por mujeres vestidas como las mujeres rurales vestían en 1950, para degustar el pan de trigo y el queso de la Ulloa locales, el grupo camina hacia los alrededores de la aldea. Y en medio del camino y desde lo alto aparece la figura del mítico "Curuxás" (Ramón Rodríguez Varela), un anarquista gallego de la CNT huido de la represión franquista, y al que el aparato franquista no consiguió detener en toda la posguerra civil española. La representación de Curuxás, encarnado por el vecino de la aldea Xusto, es la de un guerrillero antifranquista o "maquis" que defiende la República y anima a combatir la Dictadura y sus aparatos de represión (ej. la guardia civil). Esta representación relaciona política y ruralidades cuestionando varios clichés y equívocos históricos: la supuesta absoluta subordinación campesina, la falta de resistencia gallega frente a la dictadura franquista, la adhesión al régimen sin contestación. Lejos de una idealización cristalina y limpia, esta representación es comprometida con la historia (Parrado, 2009), pero también con las memorias sociales de los habitantes más viejos de la zona.

Casi llegando al final del recorrido performativo, nos encontramos con el lavadero y un grupo de mujeres lavando y dialogando sobre la vida social de la época. Y de regreso a la aldea nos asalta un hombre que nos pregunta quien ha cambiado su turno de riego de aguas. Esta escenificación del conflicto sobre el agua, tan típico en la Galicia rural de mediados del siglo XX, nos presenta de una forma teatralizada la lucha por los recursos, la conquista de la tierra por los campesinos gallegos y su defensa a ultranza, incluso hasta la muerte. Finalmente el recorrido acaba en su punto de salida, el campo de la fiesta de la parroquia, donde el grupo contempla como un grupo de hombres cavadores preparan el monte para el cultivo y también preparan trampas para cazar la perdiz.

Al remate del recorrido interpretativo y guiado, y desde un palco habilitado para el efecto se entregaron premios y se pronunciaron varios discursos en defensa de lo rural y la dinamización del mismo. Los protagonistas de los discursos son políticos, organizadores y gentes ligados a la producción cultural gallega que manejan una ideología pastoralista y naturalista, pero también patrimonialista. Algunos de los discursantes desde el palco interpretaron lo vivido como un recurso simbólico para la construcción de una nueva ruralidad gallega y por ende de la identidad nacional de Galicia. No podemos olvidar que la ruralidad ha sido para el nacionalismo gallego una fuente de recursos identitarios de la nación gallega imaginada. 
La mañana concluyó con un almuerzo con productos tradicionales como las bautizadas como "galeguesas" (hamburguesas de carne ecológica de vacas gallegas), el caldo, el pan de la aldea de Carteire, las galletas de nata "maruxas", los grelos deshidratados "Milulloa", el queso arqueixal o el licor de ortigas. La tarde continúa con una fiesta de campo animada por un grupo musical, una feria de productos artesanos y con una convivencia prolongada entre los alrededor de 400 participantes.

\section{CONCLUSIONES}

En este texto presentamos una panorámica del turismo rural en Galicia para ilustrar un caso de estudio ejemplar, particular, diferenciado y significativo de cómo se pueden establecer relaciones de complementariedad entre la actividad agrícola y el turismo (Gascón y Ojeda, 2014) orientado desde una base local. El turismo no beneficia automáticamente otras actividades económicas y menos las actividades agrarias de base local, pero mucho menos cuando se plantean políticas de substitución de la agricultura por el turismo o de separación de ambas actividades.

Si bien es cierto que hoy en día el turismo es parte del paisaje rural gallego y al mismo tiempo un elemento de transformación social rural, los caminos seguidos en el pasado no han conseguido crear una dinamización social rural importante. Lo que parecía ser un salvavidas y una panacea no se convirtió ni en lo uno ni en lo otro. La empresarialización de la actividad agraria distanció la agricultura del turismo, pero hoy en día parecen existir nuevas aproximaciones que posibilitan canalizar mejor la producción agraria y alimentar a través del turismo.

De acuerdo con Jordi Gascón (Gascón y Ojeda, 2014), la clave de un buen enlace entre agricultura y turismo está en no subordinar la agricultura local al turismo (tal como propone la teoría del enlace inducido para el turismo de nicho), y por pensar mejor en los beneficios no mercantilizados de la agricultura campesina. El caso de estudio que presentamos muestra bien esas posibilidades, y en cuanto turismo de proximidad sería una alternativa sostenible al turismo de larga distancia y a la idea de "mejor cuanto más lejos". Esto significaría un cambio en los modelos de consumo turístico, algo no muy cercano en el tiempo y con las cifras del turismo internacional a aumentar exponencialmente cada año.

El ecoagroturismo puede significar en el caso gallego no una fase ultrapasada, romántica y arcaica de la actividad agraria sino un modelo viable de producción de alimentos, una forma de mantenimiento de los ecosistemas, multifuncionalidad y soberanía alimentaria. En este sentido el turismo puede ser un amigo de lo ecológico y significar una oportunidad 
para dignificar modelos agroecológicos adecuados a cada contexto cultural. El caso de estudio presentado es algo más que un producto turístico con base local, y puede ser considerado como una filosofía de desarrollo rural en acción, un etnodesarrollo que utiliza el turismo como estrategia de adaptación a las nuevas ruralidades. 


\section{REFERENCIAS BIBLIOGRÁFICAS}

Cabana Iglesia, Ana (2008) “Tres tempos nunsó tempo: as aldeas en Galiza”,Arraianos VII, pp. 19-26.

Cañada, Ernest (2012) "Perspectivas del turismo comunitário: cómo mantener vivas las comunidades rurales?". En Joan Buades, Ernest Cañada y Jordi Gascón (coords.) El turismo en el inicio del milenio. Una lectura crítica a tres voces. Madrid: Foro de Turismo Responsable, pp. 119-122.

Cloke, P.; Marsen, T. y Mooney, P. (eds.) (2006) Handbook of Rural Studies .London: Sage. Figueira, Victor y Dias, Reinaldo (2011) Responsabilidade Social no Turismo. Lisboa: Escolar Editora.

Fleischer, Anat y Tchetchik, Aliza (2005) "Does rural tourism benefit from agriculture?", Tourism Management, 26(4), pp. 493-501.

Frutos Mejías, Luisa María y Ruiz Budría, Enrique (2012) "Los quesos con Indicación Geográfica: su importancia en el sistema agroalimentario local”. En Frutos Mejías, L.M. y Ruíz Budría, E. (coords.) Los productos con indicación geográfica en el sistema agroalimentario español. tradición y modernidad. Zaragoza: Institución Fernando El Católico, pp. 73-98.

García Sanz, Benjamín (1994) "Nuevas claves para entender la recuperación de la sociedad rural”. Papeles de Economía Española 60/61, pp. 204-218.

Gascón, Jordi (2013) "The limitations of community-based tourism as an instrument of development cooperation: the value of the Social Vocation of the Territory concept". Journal of Sustainable Tourism, 21(5), pp. 716-731.

Gascón, Jordi y Ojeda, Diana (2014) Turistas y campesinado. El turismo como vector de cambio de las economías campesinas en la era de la globalización. Madrid: Foro del Turismo Responsable - Pasos.

González Reboredo, Xosé Manuel (2009) "Elocaso del campesinado en Galicia: situación de partida, cambio y recuerdos en el presente o para el futuro". En Salvador Rodríguez Becerra y Clara Macías Sánchez (coords.) El fin del campesinado. Transformaciones culturales de la sociedad rural andaluza en la segunda mitad del siglo XX. Sevilla: Junta de Andalucía-Centro de Estudios Andaluces, pp. 237-264.

González Sousa, Sandra (2013) Puesta en valor del complejo ecoagroturístico Arqueixal. Barcelona: Universidad de Barcelona (tesis de máster en gestión del patrimonio cultural, inédita). 
Lane, Bernard (2014) "Turismo rural de segunda geração: prioridades e questões de pesquisa”. En Artur Cristóvão, Xerardo Pereiro, Marcelino de Souza e Ivo Elesbão (coords.) Turismo rural em tempos de novas ruralidades. Porto Alegre: Editora da UFRGS, pp. 15-47.

Lois, R. C.; Piñeira, M. J.; Santomil, D. (2009) "Imaxe e oferta de aloxamento no medio rural de Galicia”. Revista Galega de Economía 18(2), pp. 71-90.

Marx, Leo (1964) The Machine in the Garden: Technology and the Pastoral Ideal in America. New York: OUP.

Marx, Leo (1976) A vida no campo e a era industrial. São Paulo: Melhoramentos -EDUSP. Martínez Roget, Fidel (2004) Turismo Rural en Galicia: Contribuciones al desarrollo sostenible. Santiago de Compostela: Xunta de Galicia -Dirección Xeral de Turismo.

Murphy, Peter (1985) Tourism: A Community Approach. New York: Methuen.

Oliva, Jesús (2010) "Rural melting-pots, mobilities and fragilities: reflections on the Spanish case". Sociologia Ruralis 50(3), pp. 278-295.

Palerm, Juán Vicente (1997) Los nuevos campesinos. México: Universidad Interamericana. Parrado, Carlos (2009) Curuxás. O guerrilleiro que non cazou Franco. Vigo: Promocións Culturais.

Pardellas, Xulio (1996) "Turismo rural, turismo de habitação y cooperación transfronteriza: el sur de Galicia e o Minho Portugués”. En AA.VV. (coords.) Factores de desarrollo en regiones periféricas. Vigo: Consorcio da Zona Franca, pp. 272-287.

Pereiro, Xerardo (2005) Galegos de vila. Antropoloxía dun espazo rurbano. Santiago de Compostela: Sotelo Blanco.

Pereiro, Xerardo (2012) "El turismo responsable en Galicia: Ecoagroturismo Arqueixal". En Agustín Santana, Alberto Jonay y Pablo Díaz (eds.) Responsabilidad y Turismo en Iberoamérica. La Laguna: Pasos (e-book en www.pasosonline.org), pp. 95-122.

Pereiro, Xerardo y Prado, Santiago (2013) "Cross cultural perceptions between rural and urban in Galicia". En Luís Silva y Elisabete Figueiredo (eds.) Shaping Rural Futures. From Perceptions to Outcomes. Dordrecht: Springer, pp. 227-245.

Phillip, S.; Hunter, C. y Blackstock, K. (2010) “A typology for defining agritourism”, Tourism Management 31, pp. 754-758. 
Prado Conde, Santiago y Pereiro, Xerardo (2012) "Ecoagroturismo en Galiza: Anális comparada de dous casos de estudo”. En Xavier Simón Fernández y Damián Copena Rodríguez (coords.), Iniciativas agroecolóxicas inovadoras para a transformación dos espazos rurais. Actas del IV Congreso Internacional de Agroecología y Agricultura Ecológica. Vigo: Universidade de Vigo - Fundación Juana de Vega, pp. 213-231.

Prista, Pedro (1998) “O turismo nos campos”, En Pedro Prista (ed.) Essas Outras Histórias que Há para Contar. Lisboa: Salamandra, pp. 156-161.

Richards, Greg y Hall, Derek (eds.) (2000) Tourism and Sustainable Community Development. London: Routledge.

Rodil Fernández, Xiana (2009) O agroturismo en Galiza: Modalidade distintiva do turismo rural ? Un estudo das casas de labranza da provincia de Lugo. Ourense : Universidade de Vigo (tesis de máster en turismo, inédita).

Roigé i Ventura, Xabier (2007) “La reinvención del museoetnológico”. En Iñaki Arrieta Urtizberea (ed.) Patrimonios culturales y museos. Másallá de la historia y del arte. Donostia: Euskal Herriko Unibertsitatea (Universidad del País Vasco), pp. 19-42.

Roseman, Sharon (2008) O Santiaguiño de Carreira. O rexurdimentodunha base rural no concello de Zas. A Coruña: Baía Edicións.

Ruíz Ballesteros, Esteban (2011) "Social-ecological resilience and community-based tourism: an approach from Agua Blanca, Ecuador", Tourism Management 32, pp. 655666.

Santos, Xosé Manuel (1999) “Reflexións entorno ó papel do turismo no desenvolvemento local”. En Alcides Dos Santos y José Manuel de Mascarenhas (coords.) Desarrollo local y regional en Iberoamérica. Santiago de Compostela: Universidade de Santiago de Compostela, pp. 149-165.

Santos, Xosé Manuel y Paül, Valerià (2011) “Construíndo o turismo fluvial e de interior na Galiza”. En Rubén Lois y Paül, Valerià (eds.) Turismo fluvial e da natureza. Un elemento de revitalización dos espazos rurais e do interior. A Coruña: Instituto Galego de Estudos Europeos e Autonómicos, pp. 17-34.

Silva, Luís (2009) Casas no Campo. Etnografia do Turismo Rural em Portugal. Lisboa: ICS.

Simmard, C. (1992) “Économuseologie”. F.E.Q. Québec, pp. 7-8.

Smith, Laurajane (2006) Uses of heritage.London: Routledge.

Sparrer, Marion (2007) Turismo no espazo rural e desenvolvemento. Santiago de Compostela: Xunta de Galicia. 
Trabada Crende, Elías (dir.) (2007) Estudio sociológico sobre el territorio rural de Galicia. Santiago de Compostela: Cáritas - Fundación Foessa.

Valcárcel Riveiro, Carlos y Santos Solla, Xosé Manuel (1999) “Turismo rural, lingua e desenvolvemento local". En María Pilar Torres Luna, Rubén Lois González y Pegerto Saavedra (coords.) Espacios rurais e sociedades campesiñas. Santiago: Universidade de Santiago de Compostela, pp. 79-106.

Van der Ploeg, Jan Douwe (2010) Nuevos campesinos. Campesinos e imperios alimentarios. Barcelona: Icaria. 